\title{
GESTÃO DE RESÍDUOS SÓLIDOS E GEOTECNOLOGIAS: CONSIDERAÇÕES ELEMENTARES.
}

\author{
João Paulo Peres Bezerra'
}

\begin{abstract}
RESUMO
O texto aqui apresentado buscar expor pontualmente algumas possibilidades de utilização das geotecnologias aplicadas a gestão integrada de resíduos sólidos urbanos. Apresentando considerações teóricas elementares sobre os termos gestão e gerenciamento, bem como trazemos a legislação federal para o debate explicitando suas exigências com foco na elaboração dos planos de gestão de resíduos sólidos. É neste ponto que as geotecnologias devem ser contempladas, devido o seu grande potencial de apoio à gestão e gerenciamento dos RSU, subsidiando a partir da base cartográfica uma série de conhecimentos elementares para a gestão. . Ressaltamos que o esse texto se insere no contexto da pesquisa de doutoramento intitulada 'Gestão Integrada de Resíduos Sólidos Urbanos Municipais: Interfácies concretas e novas potencialidades, e é realizada no programa de pósgraduação em Geografia da UNESP. FCT de Pres. Prudente, sobre orientação do Prof. Dr Antonio Cezar Leal.
\end{abstract}

PALAVRAS CHAVES: Gestão de resíduos; geotecnologias; Sistema de Informação Geográfica

\section{SOLID WASTE MANAGEMENT AND GEOTCHNOLOGY: ELEMENTARY CONSIDERATIONS.}

\begin{abstract}
The text presented here seek timely expose some possible uses of geotechnology applied the integrated management of municipal solid waste. Featuring elementary theoretical considerations about the terms management and management as well as federal legislation to bring the debate explaining your requirements with a focus on planning for the management of solid waste. This is where geotechnologies must be considered, due to its great potential to support the management of MSW management and subsidizing from the basemap a series of general knowledge for management. . We emphasize that this text is in the context of doctoral research entitled 'Integrated Management of Municipal Solid Waste: Concrete Conections and new capabilities, and is held in the graduate program in Geography UNESP FCT Pres. Cautious about the direction of Phd. Antonio Cezar Leal.
\end{abstract}

KEYWORDS: waste management; geotechnology; Geographic Information System

\footnotetext{
${ }^{1}$ Mestre e Doutorando em Geografia- Área de Concentração (Análise Ambiental). Desenvolve trabalhos como consultor técnico e na docência em nível universitário. Como pesquisador atual no grupo de pesquisa GADIS da UNESP FCT de Presidente Prudente. Contatos: email: jpp_bezerra@ hotmail.com / 18991398989.
} 


\section{GESTIÓN DE RESIDUOS SÓLIDOS Y GEOTECNOLOGÍA: CONSIDERACIONES ELEMENTALES.}

RESUMEN: El texto que aquí se presenta tenga por oportuno exponer algunos de los usos posibles de la geotécnica aplicada a la gestión integral de los residuos sólidos municipales. Con consideraciones teóricas elementales sobre el manejo y la gestión de términos, así como la legislación federal para llevar el debate explicando sus necesidades con un enfoque en la planificación de la gestión de los residuos sólidos. Aquí es donde hay que considerar geotecnologías, debido a su gran potencial para apoyar la gestión de manejo de los RSM y la subvención del mapa base de una serie de conocimientos generales para la gestión. . Hacemos hincapié en que este texto está en el contexto de la investigación doctoral titulada "Gestión Integrada de Residuos Sólidos Municipales: Interfaces Concretas e nuevas capacidades, y se mantiene en el programa de postgrado en Geografía UNESP FCT Pres. Cuidado con la dirección del profesor Dr. Antonio Cezar Leal.

PALABRAS CLAVE: gestión de residuos ; geotécnica ; Sistema de Información Geográfica

\section{GESTÃO DE RESÍDUOS: PROBLEMAS GLOBAIS E AÇÕES LOCAIS}

As cidades contemporâneas apresentam relações socioeconômicas específicas, viabilizando uma nova cultura associada ao consumo extremado por alguns poucos privilegiados. Dentre as peculiaridades do meio urbano, ressaltamos o dizer de Henry Lefebrve, refletindo sobre a cidade, ele a coloca como locus onde: “[...] las necesidades se converten en deseos. Éstos tomam forma em ella passan de biológicos (es decir animales e vitales) a humanos”. (LEFEBRVE, 1970, p. 86).

Nosso cotidiano faz-se também pelas ações de cosumo de objetos e serviços a fim de satisfazer nossas necessidades que são, cada vez mais, inseridas em um ciclo infinito entre: consumo e criação de novas necessidades. Dessa forma, as comunidades urbanas contemporâneas, inevitavelmente, geram altos índices per captas de resíduos em seu viver urbano. Observando estudos elaborados pela International Solid Waste Association, em recente publicação, traz uma importante síntese do cenário global sobre a questão dos resíduos sólidos. No ISWA Annual 
Report 2013 encontra-se o enorme número de 1,84 bilhões de toneladas de resíduos e rejeitos municipais gerados ao longo de 2013.

Reduzindo nossa escala de detalhe e observando de maneira panorâmica o Brasil, que vive um importante momento para a gestão de resíduos devido à Política Nacional de Resíduos Sólidos (Lei Federal 12.305/2010), temos um cenário de grandes desafios. Dentre eles está a elaboração do Plano Nacional de Resíduos Sólidos, acompanhada pela elaboração ou atualização dos Planos Estaduais, e do Distrito Federal. As prefeituras precisam elaborar seus Planos Municipais de Gestão Integrada de Resíduos Sólidos e extinguirem os lixões². A Tabela 1 traz as quantidades geradas diariamente no território brasileiro, fundamentalmente no meio urbano.

Tabela: 1. Quantidade diária de RSU e/ou públicos encaminhados para destinação final.

\begin{tabular}{lrr}
\hline Unidade de análise & Destinação final & (t/dia) \\
Brasil & 2000 & 2008 \\
& 140.080 & 188.815 \\
& Destinação Final por habitante urbano & $(\mathrm{kg} / \mathrm{hab}$. dia) \\
& 2000 & 2008 \\
Brasil & 1 & 1,2 \\
\hline \hline Fonte: Plano Nacional de Resíduos Sólidos (BRASIL, 2012). Adaptado.
\end{tabular}

Ainda na tentativa de traçar um panorama geral brasileiro, observamos os dados referentes à quantidade de resíduos e rejeitos, agrupados em suas formas de destinação final, a saber: lixão, aterro controlado e aterro sanitário por toneladas/dia, e ainda por tamanho dos municípios. Vejamos o Quadro 1.

\footnotetext{
${ }^{2}$ Lixão são locais onde se dispõe irregularmente os rejeitos e resíduos urbanos. De acordo com a nova lei 12.305/2010 estes locais devem ser encerrados e fechados para a construção de aterros sanitários com a disposição controlada por técnicas adequadas.
} 
Quadro 1: Quantidade de resíduos e rejeitos (lixão, aterro controlado e aterro sanitário (t/dia).

\begin{tabular}{|l|r|r|r|r|r|r|}
\hline \multirow{2}{*}{$\begin{array}{l}\text { Unidade de } \\
\text { análise }\end{array}$} & \multicolumn{2}{|c|}{ Lixão } & \multicolumn{2}{c|}{ Aterro Controlado } & \multicolumn{2}{c|}{ Aterro sanitário } \\
\cline { 2 - 7 } & $\mathbf{2 0 0 0}$ & $\mathbf{2 0 0 8}$ & $\mathbf{2 0 0 0}$ & $\mathbf{2 0 0 8}$ & $\mathbf{2 0 0 0}$ & $\mathbf{2 0 0 8}$ \\
\hline PNSB & $45.484,70$ & $37.360,80$ & $33.854,30$ & $36.673,20$ & $49.614,50$ & $110.044,40$ \\
\hline Brasil & $45.484,70$ & $37.360,80$ & $33.854,30$ & $36.673,20$ & $49.614,50$ & $110.044,40$ \\
\hline $\begin{array}{l}\text { Muni. } \\
\text { pequenos }\end{array}$ & $34.533,10$ & $32.504,30$ & $10.405,90$ & $14.067,90$ & $6.878,40$ & $32.420,50$ \\
\hline Muni. médios & $10.119,60$ & $4.844,50$ & $15.525,50$ & $17.278,30$ & $17.105,80$ & $45.203,40$ \\
\hline $\begin{array}{l}\text { Mun. } \\
\text { grandes }\end{array}$ & 832 & 12 & $7.922,90$ & $5.327,00$ & $25.630,30$ & $32.420,50$ \\
\hline
\end{tabular}

Fonte: Plano Nacional de Resíduos Sólidos (BRASIL, 2012).

Observando a quantidade de resíduos destinados para o grupo 'lixões', percebemos a concentração de resíduos destinados inadequadamente na classe dos municípios pequenos e, ademais, percebe-se que o avanço das melhorias se concentra nos municípios grandes. A partir das observações citadas, entendemos que o problema se pulveriza por uma extensa rede de pequenos municípios onde se tem uma menor geração de resíduos in loco, porém os conhecimentos técnicos e os recursos financeiros são mais escassos, o que pode explicar o pequeno avanço do grupo 'municípios pequenos' nos processos de adequação municipal previstos na Lei $12.305 / 2010$.

É exatamente na escala municipal onde teremos a possibilidade de ações locais, visto a responsabilidade do município e ainda a materialidade do problema nesta escala, uma vez que a gestão $\Leftrightarrow$ gerenciamento efetivo dos resíduos sólidos acontece na escala local (no município), exatamente onde podemos aplicar metodologias, técnicas e geotecnologias no dia-a-dia da limpeza pública e gerenciamento dos resíduos municipais.

\section{LEGISLAÇÃO FERDERAL E GESTÃO $\Leftrightarrow$ GERENCIAMENTO}

No Brasil a gestão integrada de Resíduos Sólidos Urbanos é uma responsabilidade do ente municipal, como está previsto na Constituição Federal, em seu Art. 23, nos Incisos VI e IX que tratam da proteção ambiental, onde se lê: "é de competência da União, dos estados, do Distrito Federal e dos municípios proteger o 
meio ambiente e combater a poluição e promover programas de construção de moradias e saneamento ambiental". (BRASIL, 1988).

Em seu Art. 30, Inciso I, que explicita a competência municipal para legislar sobre assuntos locais. Desta maneira, os serviços e tarefas voltadas à gestão integrada dos resíduos sólidos urbanos devem ser oferecidos pelo poder público municipal, seja no regime de concessão ou permissão, a realização de tais serviços fica sobre a obrigatoriedade do ente municipal, conforme o Inciso $V$ do mesmo artigo como nos lembra (BARROS, 2012, p. 12).

A Lei 10.257 de 2001 promulga o Estatuto das Cidades, e em seu Art. $2^{\circ}$ Inciso I, vem garantir a todos o direito a cidades sustentáveis. Direito este "[...] entendido como o direito à terra urbana, à moradia, ao saneamento ambiental, à infraestrutura urbana, ao transporte e aos serviços públicos, ao trabalho e ao lazer, para às presentes e futuras gerações". (BRASIL, 10.257/2001). E ainda, em seu Artigo $2^{\circ}$ no Inciso II explicita a "gestão democrática por meio da participação da população e de associações representativas dos vários segmentos da comunidade na formulação, execução e acompanhamento de planos, programas e projetos de desenvolvimento urbano" como uma diretriz para a gestão pública municipal. (BRASIL, 10.257/2001). Assim, a Lei 10.257/2001 e a 12.365/2012 regulamentam os Arts. 182 e 183 da Constituição Federal, cujo objetivo é estabelecer normas de interesse social e de ordem pública afim de regular o uso da propriedade urbana para o bem coletivo, assegurando o bem estar do cidadão, sua segurança e ainda o equilíbrio ambiental para os munícipes. (BARROS, 2012, p. 13).

A PNRS explicita a existência de onze classes de resíduos e rejeitos, em seu Art. 13, classificados de acordo com a sua origem sendo: domiciliares, de limpeza urbana, resíduos sólidos urbanos, resíduos de estabelecimentos comerciais e prestadores de serviço, de serviço público de saneamento básico, resíduos industriais, resíduos de serviço de saúde, resíduos de construção civil, resíduos agrossilvopastoris, de serviço de transporte e resíduos de mineração. Os resíduos e rejeitos também são classificados quanto sua periculosidade, sendo agrupados em perigosos ou não perigosos. 
Outro ponto importante a ser ressaltado da Política em questão, são os planos de resíduos que deverão ser elaborados, de acordo com conteúdo mínimo presente no Decreto Federal 7.404/2010. Tais planos, previstos no Art. 14 da 12.305/2010, contemplam uma significativa multiplicidade escalar que abrange desde o plano nacional, planos estaduais de resíduos sólidos, planos de resíduos microrregionais e de regiões metropolitanas ou aglomerações urbanas, planos intermunicipais de resíduos sólidos, os planos municipais de gestão integrada de resíduos sólidos e os planos de gerenciamento de resíduos sólidos.

Vejamos então a definição o para o termo gestão no dicionário Houaiss (2009), "ato ou efeito de gerir; administrar; gerência; gestão", para o termo gerir, define-se como: "exercer gerência sobre; administrar; gerenciar." Já o termo Gerenciamento se encontra como, "ação ou efeito de gerenciar, gerência". Por sua vez o termo gerenciar significa "dirigir (empresa, negócio, serviço) na condição de gerente, administrar; gerir; organizar automaticamente um conjunto de operações". Houaiss (2009).

Temos em CEMPRE (2010) uma definição significativa para o termo gerenciamento integrado do lixo municipal, vejamos:

O Gerenciamento Integrado do Lixo Municipal é um conjunto articulado de ações operacionais, financeiras e de planejamento que uma administração municipal desenvolve (com base em critérios, sanitários, ambientais e econômicos) para coletar, segregar, tratar e dispor o lixo de sua cidade. CEMPRE (2010, p.3).

A Política Nacional de Resíduos Sólidos também faz uma diferenciação conceitual entre os termos Gestão e Gerenciamento:

Art. $3^{\circ}$ Para os efeitos desta Lei, entende-se por: [...]

$X$ - gerenciamento de resíduos sólidos: conjunto de ações exercidas, direta ou indiretamente, nas etapas de coleta, transporte, transbordo, tratamento e destinação final ambientalmente adequada dos resíduos sólidos e disposição final ambientalmente adequada dos rejeitos, de acordo com plano municipal de gestão integrada de resíduos sólidos ou com plano de gerenciamento de resíduos sólidos, exigidos na forma desta Lei;

$\mathrm{XI}$ - gestão integrada de resíduos sólidos: conjunto de ações voltadas para a busca de soluções para os resíduos sólidos, de forma a considerar as dimensões política, econômica, ambiental, cultural e social, com controle social e sob a premissa do desenvolvimento sustentável; 
Tais definições nos servem para um maior entendimento sobre estes termos, ressaltamos que esta diferenciação entre gestão e gerenciamento não é aceita por toda comunidade gestora e acadêmica, mas para o nosso enfoque, tal diferenciação é eficaz e traz em seu conteúdo bases para efetivar a visão sistêmica na gestão de resíduos sólidos.

A Gestão de Resíduos Sólidos demanda uma escala temporal que não pode se ater apenas ao tempo de um mandato ou de um governo, mas sim, buscar metas e cenários de médio e longo prazo. Tais perspectivas devem estar presentes nos processos de planejamento e gestão de resíduos sólidos, assim, a concepção de Gestão de Resíduos Sólidos se amplia, dando espaço para a participação popular na elaboração de metas e cenários a serem atingidos por um município ou região.

\section{GEOTECNOLOGIAS: NOÇÕES ELEMENTARES}

O termo Geotecnologias é utilizado de maneira múltipla, principalmente nos segmentos de mercado e no chamado senso comum. Não é nosso objetivo, debater questões epistemológico-ontológicas das Ciências da Geoinformação ou explicitar um debate sobre a significação conceitual dos termos geo-informação, geoprocessamento, geomática ou geotecnologias. O que faremos são apenas algumas colocações fundamentais para o entendimento básico da questão.

Os trabalhos que deram origem ao sistema de atual desenvolveram o Sistema de Informações Geográficas (SIG), foram realizados pelo Departamento Canadense de Florestas e Desenvolvimento Regional, como um marco pioneiro. Estes trabalhos buscavam quantificar e cartografar os recursos naturais canadenses, desenvolvendo, no início dos anos 1960, o Sistema de Informações Geográficas Canadenses (CGIS Canadian Geographic Information System). (LANG \& BLASCHKE, 2009).

Nos tempos atuais o desenvolvimento desta área do saber, se encontra bem avançado se comparado com os anos 1960, havendo autores que vislumbram a possibilidade de um novo campo da ciência. Assim, eleva-se o debate, para uma possível construção de uma nova disciplina chamada "Geographical Informantion 
Science", devido à existência de simpósios e conferencias especificas ao tema, a existência de periódicos dedicados, assim como o corpo teórico-metodológico já existente faz com que autores, como Longley et. al. (2001) e Goodchild (1992) defenderem a construção de uma nova disciplina chamada "Geographical Informantion Science".

O avanço da utilização dos SIG's por usuários em nível de escritório, ou seja, por gestores e não apenas por programadores ou especialistas, tem suas bases nos trabalhos do Environmental Systems Research Institute de Redlands- California (EUA). Fundado em 1969, onde as equipes desenvolveram muitas facilidades e softwares para SIG, baseados em computadores de fácil utilização, resultando em meados de 1990 na criação do Desktop - GIS Arc View ESRI. (LANG \& BLASCHKE, 2009). Tal aplicativo hoje se encontra na versão 10.1 sendo um software muito poderoso. Seu acesso, porém, é restrito por conta dos altos custos de suas licenças.

O marco do início dos debates e trabalhos desta área no Brasil se deu em 1982, quando, a convite de um grupo de profissionais liderados pelo Prof. Dr. Jorge Xavier da Silva (UFRJ), o Dr. Roger Tomlinson (uma das figuras mais importantes no desenvolvimento do CGIS) visitou o País. (CAMARA.; DAVIS.; MONTEIRO, 2001). No departamento de Geografia da (UFRJ), sob coordenação do Prof. Dr Jorge Xavier da Silva, temos a elaboração do Sistema de Análise Geo-Ambiental - SAGA, um software com grande capacidade de análise geográfica e muito utilizado no meio acadêmico. Na região Sul do país surgiram, a partir de trabalhos da empresa de aerolevantamentos (a AeroSul) um sistema de automação de processos cartográficos. Mais tarde, com a criação da empresa maxiDATA surge o MaxCAD e o dbMAP com foco em aplicações cadastrais. Nos anos noventa a TELEBRÁS desenvolveu o Sistema Automatizado de Gerencia de Rede Externa (SAGRE) sendo assim uma significativa aplicação do geoprocessamento à telefonia brasileira.

(CAMARA; et.al. 2001)

No Instituto Nacional de Pesquisas Espaciais (INPE), ainda na década de 1980, foi criada a Divisão de Processamento de Imagens. Os trabalhos ali desenvolvidos resultaram no inicio dos anos noventa no SISTIM - Sistema de Tratamento de Imagens, muito utilizado em trabalhos para a EMBRAPA e 
PETROBRÁS. Com o avanço dos trabalhos, o INPE lança o software SPRING, que vem unificar o tratamento de imagens de sensoriamento remoto com mapas temáticos, cadastrais e modelos numéricos do terreno. (CAMARA; DAVIS; MONTEIRO; 2001). Atualmente os softwares mais conhecidos no Brasil quando se pensa em SIG, Geoprocessamento e Sensoriamento Remoto são: Arc GIS® 10.1 ESRI; SPRING 5.2.6 -INPE; Qauntun Gis 2.4 -OS GEO; IDRISE® - Clark Labs; ERDAS $\AA$ - Exagon Geospatial, MAP INFO ${ }^{\circledR}-$ Pitney Bowes e o Gv SIG-Conselleria d'Infraestructure i Transports (CIT - Valencia) entre outros menos conhecidos.

Com suas múltiplas aplicações em diversos setores da atual forma de organização societal, que se encontra estruturada fundamentalmente na tríade, ciência-técnica-informação, como explicitada por SANTOS (1996), as Ciências da Geoinformação ganham a cada dia mais importância. As Ciências da Geoinfomação, tomam, como escopo de estudo "a implementação de diferentes formas de representação computacional do espaço geográfico" como bem mostra Camara e Monteiro (2001).

Gostaríamos de explicitar a importância dos paradigmas acima, e que para esta reflexão pontual, expressa neste pequeno texto, iremos considerar o termo Geotecnologias uma noção que permeia debates acadêmicos e o senso comum. Cujo amplo escopo contempla, vários campos do conhecimento como o Geoprocessamento, Sensoriamento Remoto, Geomática e a Cartografia Digital. E esta interdisciplinaridade se mostra tanto nas elaborações e soluções já existentes na materialidade dos softwares, quanto nas soluções de hardwares e peoplewares.

Partindo das premissas elementares expressas acima, buscamos entender um pouco mais sobre os chamados Sistemas de Informações Geográficas, os quais acreditamos, ser uma potente ferramenta de sistematização e análise de dados e ocorrências espaciais que pode contribuir em muitos aspectos com a gestão de RSU.

Lembremos as colocações de CLARK (1995), sobre a importância da base cartográfica como a estrutura fundamental para o SIG, que deve contemplar e obedecer a princípios elementares de cartografia com atenção ao elipsoide de referencia, ao datun geodésico, à projeção cartográfica, precisão e generalização das informações. 
Outro componente do que aqui chamamos de SIG é o sistema de radionavegação conhecido como GPS. Os principais sistemas são o sistema norte americano Navigation Satellite with Time and Ranging - GPS e o sistema russo Glonass. Ainda temos os trabalhos da comunidade europeia que vem desenvolvendo o sistema Galileo (BITAR, 2005). Estes sistemas de navegação fornecem a base das operações de monitoramento de veículos e equipes de trabalho, cuja aplicação na gestão de resíduos sólidos já é uma realidade no Brasil.

Nesta oportunidade gostaríamos de ressaltar a etapa fundamental para a elaboração de um SIG, a base cartográfica, seguindo explicitamos as rotinas de trabalho para o desenvolvimento de materiais elementares como o Modelo Numérico do Terreno (MTN) e um conjunto de análises voltadas à Geomorfologia, que muito podem contribuir para a Gestão e para o Gerenciamento de RSU. No caso em questão, apresentamos uma rotina de trabalho onde se utiliza o software Arc GIS $\circledast$, porém ressaltamos que os gestores e pesquisadores podem utilizar outros softwares livres, como, por exemplo, o SPRING ou Quantum GIS.

Neste momento queremos expor uma possibilidade de aplicação das geotecnologias nas etapas de planejamento da gestão de RSU. Entendemos que não seja possível a elaboração de um plano de resíduos municipais sem a existência de bases cartográficas municipais que viabilizem levantamentos de informações elementares para a tal. Dessa forma, elaboramos alguns apontamentos sobre como se pode montar uma base cartográfica elementar a ser utilizada na elaboração destes planos municipais. O objetivo é elaborar uma base cartográfica digital, obviamente dotada de georreferenciamento, que tenha em sua estrutura básica informações voltadas à Gestão de Resíduos Sólidos.

Primeiramente devemos atentar para a veracidade e acurácia das informações a serem compiladas, este aspecto estará diretamente ligada ao nível técnico da equipe envolvida. Os trabalhos devem se iniciar pela adoção de referenciais geodésicos e projeções cartográficas. No caso brasileiro recomendamos a projeção Universal Transversa de Mercator (UTM) que viabiliza a interpolação de coordenadas, medidas de distancias, cálculo de ângulos e de áreas. Quanto aos referencias geodésico deve-se adotar o SIRGAS 2000 como datum geocêntrico. 
Outro ponto a ressaltar, é a importância de admitirmos as convenções cartográficas, na elaboração da base cartográfica em questão, obviamente devemos ressaltar a importância do Cadastro Territorial Multifinalitário (CTM) como instrumento não só da política e gestão fiscal do município mas também como instrumento técnico para a gestão ambiental urbana. Por conta disso, o CTM faz-se também um potencial instrumento para a gestão e gerenciamento das operações da Gestão Integrada dos RSU. Infelizmente, sabemos que a grande maioria dos municípios ainda não montaram seus cadastros territoriais, e sequer, o farão nos próximos anos. Isso nos leva a optar neste texto por fazer uma exposição mais detalhada de como montar uma base cartográfica elementar.

Para as etapas de coleta domiciliar ou seletiva e transbordo, apontamos no Quadro 1, alguns produtos que contribuem significativamente para a GIRSU, e também para a limpeza pública urbana nas operações de varrição manual ou mecânica.

Quadro 1: Técnicas e produtos e suas aplicações e benefícios para a gestão.

\begin{tabular}{|c|ll|}
\hline Montagem de Base de Dados cartográficos: & Elaboração de Roteiros de Coleta Domiciliar a \\
- MNT - a partir de bases topográficas & partir das Unidades de Relevo, fornece uma \\
IBGE série 1:50.000 / IGC 1:10.000 & boa noção do tempo de operação em cada \\
/vetorizadas ou utilização do SRTM & setor pode prever possíveis riscos; \\
- Carta Hipsométrica & Otimização do Planejamento e operação da \\
- Carta de declividades e declividades & Varrição Manual e Mecânica; \\
médias, & Setorização e Roteirização da Coleta \\
Identificação de linhas de cumeada & Domiciliar; \\
Identificação de topos, vertentes e & Deve ser critério para a locação de Locais de \\
fundos de vale; & Entrega Voluntária, e para locação de \\
Mapeamento de Unidades de Relevo & containers de acondicionamento; \\
(identificar áreas de maior e menor & Projeção detalhada de custos (R\$ /Km / Hora \\
complexidade operacional). & ) e (Km/ manutenção) , de frota de caminhões \\
& da coleta.
\end{tabular}

Fonte: Elaboração do autor. 
Como podemos perceber, com a aplicação de técnicas elementares podemos conseguir uma melhor logística de rotas, a partir do conhecimento detalhado das características do relevo, fundamentalmente a declividade, a qual vai determinar as condicionantes operacionais da coleta, domiciliar e seletiva. As determinantes geomorfológicas podem indicar áreas onde o tempo de coleta será maior devido à alta declividade, ou ainda pode contribuir de maneira estrutural para a elaboração de rotas de coleta, evitando, quando possível, trajetos de declive acentuado e priorizando trajetos pelas linhas de cumeada ou de declividades médias mais tênues.

Nas questões de limpeza pública urbana, como por exemplo, na varrição manual ou mecânica de calçadas, meio fio e sarjetas, o conhecimento detalhado sobre a declividade é fundamental. Observando os escritos de CEMPRE (2010), temos apontamentos importantes para a elaboração dos planos de varrição municipal, onde é citada a necessidade de mapeamentos como: topografia tipo de pavimentação, uso do solo, extensão das vias e outros condicionantes. Neste caso, a topografia se refere à declividade das vias a serem varridas e limpas, a declividade é muito significativa no que tange a produtividade das equipes, sendo as vias de maior declive os locais que levarão mais tempo para serem limpas. Dessa forma as características do relevo devem ser consideradas para o bom dimensionamento das equipes e para fomentar melhores condições de trabalho para varredores e coletores.

Para a elaboração da base cartográfica - e respectiva a construção do Mapa Base - de um dado município, o primeiro passo é a junção das cartas topográficas, cuja escala original de 1:50.000 IBGE (1974-1975), as cartas topográficas citadas, que se encontram disponibilizadas em formato TIFF, PDF, DGN no sitio eletrônico <www.ibge.gov.brlgeocienciaslcartastográficas>.

O procedimento para o georreferenciamento das cartas topográficas pode ser realizado no software Arc Map 9.3.1®, onde se inicia com a importação da imagem em formato TIFF. O georreferenciamento é feito atribuindo-se a um pixel da imagem um valor de um par de coordenadas $(X, Y)$. Para tanto utiliza-se o conjunto de ferramentas: Barra de Ferramentas - Georeferencing - Add control - Recify. Tal procedimento se repete sempre que for necessário inserir uma nova carta topográfica ou imagem não georeferenciada no SIG em elaboração. 
Passamos então para a vetorização das feições representativas, neste caso as curvas de nível e outras feições de interesse. Para tanto, cria-se um arquivo SHP polyline e inserindo neste arquivo, a criação de vetores sobre as linhas hipsométricas representadas pela carta do IBGE, e atribui-se a cota $Z$, referente a cada linha hipsométrica, ao seu vetor correspondente. Desta maneira temos as informações cartográficas para a elaboração do Mapa Base

Outra maneira de elaborar uma base de informações altimétricas de um dado município é a utilização de imagens de radar SRTM v4, disponíveis em $<$ srtm.csi.cgiar.org/>. A resolução espacial das imagens SRTM, em sua grande maioria, é de 90 metros (cada pixel da imagem equivalem a 90 metros de lado em campo, ou seja, um área de $8.100 \mathrm{~m}^{2}$ em campo). Esta definição inviabiliza seu uso para a GIRSU, assim pode-se utilizar então o método de Spline para interpolação dos dados altimétricos reduzindo a escala espacial das informações.

Para tal procedimento faz-se uso da ferramenta encontrada no Arc ToolBox® chamada Raster Interpolation > Spline, tal procedimento gera uma nova imagem Raster e esta segunda imagem Raster com resolução espacial de 5 metros ou seja, cada pixel equivale a 5 metros de lado em campo ou uma área de $25 \mathrm{~m}^{2}$ em campo, e então temos uma informação em nível de detalhamento adequado.

Assim a partir desta nova imagem Raster, cuja resolução espacial será de 5 metros, podemos partir para a elaboração do Mapa Hipsométrico a partir da classificação manual da imagem, este procedimento é realizado acessando o Layer Properties da imagem em Show: classified >classification > define interval >classify > methode > define interval. Aconselhamos a escolha do intervalo (Interval Size) de 20 metros no campo para cada classe hipsométrica. Esta importante informação é expressa nos Mapas de Declividade em Graus e Porcentagem, para tanto, pode ser utilizada as imagens de radar SRTM v4 disponíveis em <srtm.csi.cgiar.org/> e processadas, conforme descrição já explicitada. O Mapa de Declividade em Graus é elaborado partir da imagem raster com resolução espacial de 5 metros utilizando a ferramenta Spatial Analistic >Raster Surface > Slope >Output measure = Degree. Para o Mapa de Declividade Porcentagem o procedimento se altera apenas na interface output Measure $=$ Percent_rise. De posse destas informações, podemos 
realizar um bom planejamento da coleta domiciliar com sua apropriada roteirização e setorização de equipes, buscando reduzir custos da taxa de coleta municipal e melhorias para os trabalhadores envolvidos na coleta domiciliar e seletiva.

$\mathrm{Na}$ etapa de destinação final dos resíduos sólidos urbanos, temos grandes possibilidades de aplicação dos conhecimentos Geomorfológicos e Pedológicos. Nesta oportunidade não temos o objetivo de explicitar, um procedimento metodológico adequado para a definição de possíveis aterros sanitários, mas sim de explicitar e reforçar as potencialidades do uso dos SIG's em processos de definição de áreas adequadas para a destinação final de resíduos sólidos urbanos e ainda em seu monitoramento ambiental de percolados e efluentes. Vejamos algumas possibilidades diretas no quadro dois.

Quadro 2. Aplicações diretas para a destinação final de resíduos.

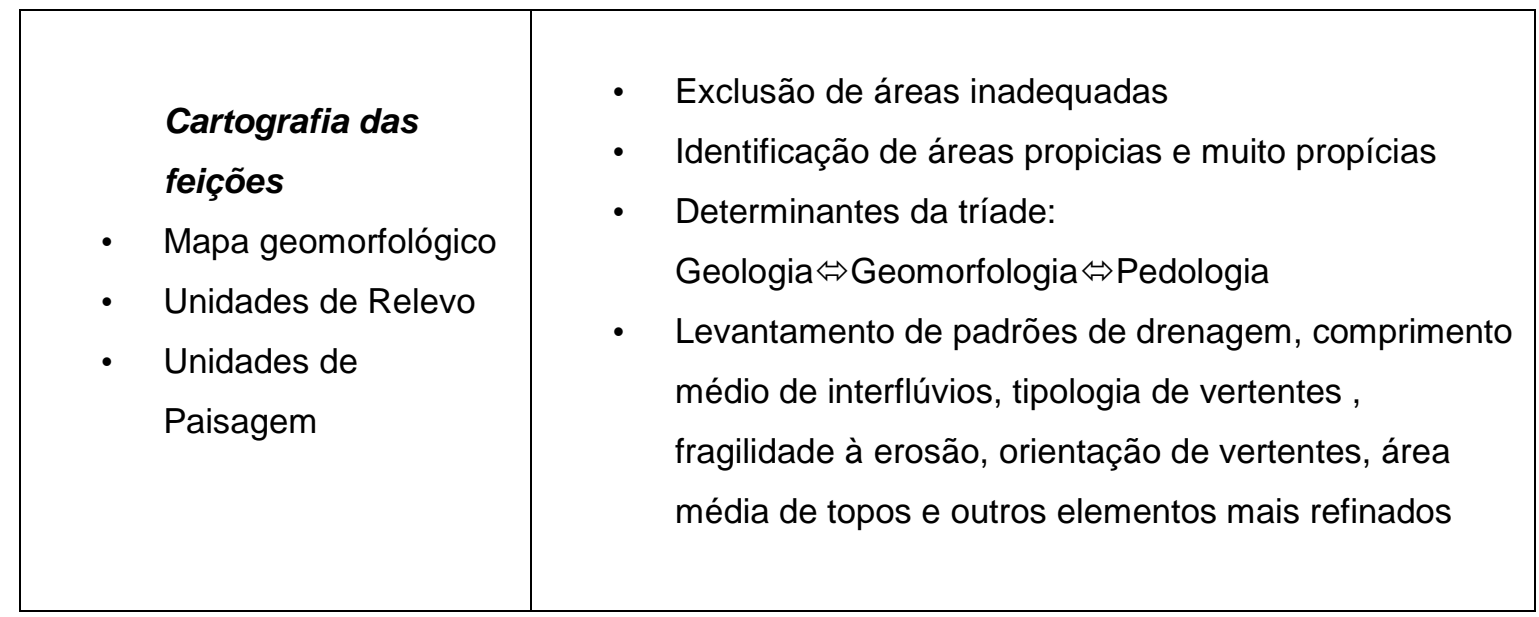

Fonte: Elaboração do autor.

Como preconiza a Lei $12.305 / 2010$ e seu decreto regulamentador, os lixões devem ser fechados e os municípios devem escolher e apontar novas áreas para a destinação final de seus resíduos e rejeitos urbanos. Por conta de nossas experências, optamos por focar uma parte do processo de licenciamento ambiental de novos aterros no estado de São Paulo, especificamente, os aterros com capacidade acima de 10 toneladas por dia. Para o licenciamento ambiental de novos aterros sanitários ou em valas, são necessários um conjunto complexo de estudos, compilados em um Estudo de Impacto Ambiental e seu respectivo relatório. Porém 
vamos observar apenas partes destas normas e solicitações do órgão ambiental competente, no caso do estado de São Paulo, a CETESB.

As informações devem propiciar o diagnóstico da área de influência do empreendimento, refletindo as condições atuais dos meios - físico-biológico e socioeconômico. É importante que se as informações possam ser inter-relacionadas, resultando num diagnóstico integrado, a fim de permitir a avaliação dos impactos resultantes da implantação do empreendimento. Desta maneira, seguindo o roteiro oficial da CETESB, disponível em www.cetesb.sp.gov.br, deverão ser apresentadas as informações abaixo relacionadas, devendo as mesmas, quando couber, ser apresentadas em planta planialtimétrica em escala compatível, e também através de imagens (fotos, fotos aéreas, imagens de satélite, etc) datadas, com legendas explicativas da área do empreendimento e do seu entorno Vejamos: Capacidade de Suporte do Solo; Proximidade de Núcleos Habitacionais; Proximidade dos Corpos Hídricos; Profundidade do Lençol; Permeabilidade do Solo; Disponibilidade de Qualidade do Material para recobrimento; Condições de Sistema Viário, Transito e Acesso; Isolamento Visual da Vizinhança; Legalidade da Localização.

\section{CONSIDERAÇÕES FINAIS}

Mostramos um conjunto de informações que podem ser inseridas em um Sistema de Informação Geográfica aplicado à Gestão $\Leftrightarrow$ Gerenciamento de Resíduos Sólidos, fundamentalmente nas etapas relacionadas diretamente com da destinação final. Sabemos da existência de muitos trabalhos para escolha de áreas para aterros, mas nosso foco buscou uma visão integralizadora, explicitando aqui algumas considerações de como é possível elaborar uma base cartográfica elementar e quais os elementos básicos devem estar presentes.

Sabemos que tais aplicações demandam certa experiência das equipes envolvidas na questão, porém, o acesso à informação e a crescente popularização das Geotecnologias podem possibilitar o uso das tecnologias e softwares dedicados aos Sistemas de Informação Geográfica aplicados à gestão integrada de resíduos sólidos. Assim, acreditamos que o SIG como ferramenta para o planejamento $\Leftrightarrow$ 
gestão $\Leftrightarrow$ gerenciamento possa contribuir para a elaboração de um planejamento participativo melhorando e otimizando as tarefas operacionais do dia a dia de quem esta a frente das questões nos mais de cinco mil municípios brasileiros.

\section{REFERENCIAS}

BARROS. R. M. Tratado sobre resíduos sólidos: gestão, uso e sustentabilidade. Rio de janeiro: Interciência; Minas Gerais: Acta, 2012.

BITAR. V. Praticando a Geografia: técnicas de campo e laboratório em geografia e análise ambiental. São Paulo, Oficina de Textos, 2005.

BRASIL. Constituição da República Federativa do Brasil, 1998. Disponível em: <http://www.planalto.gov.br/ccivil_03/constituicao/constituicao.htm> Acesso em: 08/05/2014.

BRASIL. Decreto Federal 7.404/2010. Disponível em: <http://www.planalto.gov.br/ccivil_03 /_ato20072010/2010/Decreto/D7404.htm> Acesso em: 04/01/2014.

BRASIL. Política Nacional de Resíduos SólidosLei Federal 12.305/2010. Disponível em: <http://www.planalto.gov.br/ccivil_03/_ato2007-2010/2010/lei//12305.htm> Acesso em: 02/02/2014.

BRASIL. Plano Nacional de Resíduos Sólidos. 2012 Disponível em: <http://www.sinir. gov.br/documents/10180/12308/PNRS_Revisao_Decreto_280812.pdf/e183f0e7-5255-4544-b9fd15fc779a3657> Acesso em: 03/05/2014.

CEMPRE. Lixo Municipal: Manual de Gerenciamento Integrado. 3aㅡ ed. São Paulo. 2010 CAMARA. G. \& DAVIS. C. \& MONTEIRO. A. M.V. Introdução à Ciência da Geoinformação. INPE, São José dos Campos, 2001. Disponível em: <http://mtc-2.sid. inpe.br/col/sid.inpe.br/sergio/2004/04.22.07.43/doc/publicacao.pdf> Acesso em: 02/02/2014.

GOODCHILD, M. F. Geographical Information Science. In: Jornal of Geographical Information Systms 1992.

HOUAISS, A. Dicinonário Houaiss de Lingua Portuguêsa. Ed Objetiva /Moderna, 2009.

IBGE. Série Cartas Topográficas 1: 50.000 00, 1974 e 1975. Disponível em: <www.ibge. gov.brlgeocienciaslcartastográficas> Acesso em: 03/02/2014.

LANG, S. \& BLSCHKE, T., 2009. Analise da Paisagem com SIG. Tradução Herman Kux. São Paulo Oficina de Textos, 2009.

LEFEBRVE. H, De ló Hural AL Lo Urbano. Tradução de Javier Gozález-Pueyo. Cultura Libre, Barcelona. 1974.

LONGLEY, P. A. et. al. Geographic information science and systems. Jhon Wiley \& Sons, New York. 2001.

LOPES, A. Gestão e Gerenciamento Integrado de Resíduos Sólidos Urbanos: Alternativa para pequenos municípios. Dissertação de Mestrado, Dep. De Geograifa FFLCH-USP, 2003. 
Volume 10, Número 4, 2014

Dilemas da

Sustentabilidade Urbana

ISWA. Annual Report 2013.Disponível em: <http://www.iswa.org/media/publications/ knowledgebase/> Acesso em: 25/02/2014.

ROSA. R \& Brito. J.L.S. Introdução ao Geoprocessamento: Sistema de Informação Geográfica. Uberlândia, EDUFU, (1996).

ROSA. R. Geotecnologias na Geografia Aplicada. Revista do Departamento de Geografia; $n$ 16, 2005. 